\title{
Modelagem Matemática da Cinética das Curvas de Secagem da Amêndoa do Baru (Dipteryx alata).
}

\author{
Abraham D G Zuniga $\quad$ Layse Ribeiro
}

\author{
Paulo Cléber M. Teixeira \\ Universidade Federal do Tocantins - Colegiado de Engenharia de Alimentos. \\ 77006-492, Campus Universitário de Palmas, TO \\ E-mail: clebermt@uft.edu.br
}

\section{RESUMO}

Esta pesquisa representa um estudo da Cinética das curvas de Secagem da Amêndoa do Baru (Dipteryx alata), os modelos são, geralmente, derivados da simplificação de uma solução em série derivados da simplificação de uma série da segunda Lei de Fick, que expressa que o fluxo de massa por unidade de área proporcional ao gradiente de concentração de água [1,2]. A secagem é uma operação que consiste na aplicação de calor e a remoção parcial ou total do teor de água de um produto através da evaporação, com o objetivo de aumentar a vida de prateleira do produto [3].

O estudo e emprego de modelos matemáticos são utilizados por vários pesquisadores para prognosticar o fenômeno da secagem, os quais serão ajustados aos dados coletados durante o processo, e são necessários para a otimização do mesmo [4].

O presente trabalho visou determinar a cinética da secagem da amêndoa (Dipteryx alata), nas temperaturas de 50,60 , e $70{ }^{\circ} \mathrm{C}$, definindo o melhor modelo ajustado.

As cinéticas de secagem foram desenvolvidas no LAPSDEA da UFT. Os experimentos foram realizados em triplicata, com a velocidade do fluxo $1,75 \mathrm{~m} / \mathrm{s}$ e da temperatura $(50,60 \mathrm{e}$ $70^{\circ} \mathrm{C}$ ). Nos primeiro 50 minutos, pesava-se a bandeja em balança digital (GEHAKA Linha $\mathrm{Bg}$ 4000 - precisão: 0,01g) num intervalo de 10 minutos, em seguida, mas cinco pesagens, o intervalo passou a ser de 20 minutos e depois mas cinco pesagens e o intervalo passou a de 30 minutos até que o peso da amêndoa ficasse constante. Para o cálculo da razão de umidade (RU), utilizou-se a expressão:

$$
R U=\frac{\left(x-X_{E}\right)}{\left(x_{i}-X_{e}\right)}
$$

Em que: $\mathrm{X}$ - teor de água do produto, decimal b.s.; $\mathrm{X}_{\mathrm{i}}$ - teor de água inicial do produto, decimal b.s.; e $\mathrm{X}_{\mathrm{e}}$ - teor de água de equilíbrio do produto, decimal b.s.

As curvas de secagem foram ajustadas utilizando-se três diferentes equações empíricas

Modelo de Newton:

$$
\begin{aligned}
& R U=e^{-k t} \\
& R U=a \cdot e^{-k t} \\
& R U=a \cdot e^{-k t}+b
\end{aligned}
$$

Em que: RU é a razão de umidade; $\mathrm{k}$ é a constante de secagem por minuto, a, e b são os coeficientes dos modelos; e t é o tempo de secagem, em minutos.

\begin{tabular}{|c|c|c|c|c|c|c|c|c|c|c|c|c|}
\hline & \multicolumn{4}{|c|}{$50^{\circ} \mathrm{C}$} & \multicolumn{4}{|c|}{$60^{\circ} \mathrm{C}$} & \multicolumn{4}{|c|}{$70^{\circ} \mathrm{C}$} \\
\hline & $\mathrm{R}^{2}$ & $\mathrm{k}$ & $\mathrm{a}$ & $\mathrm{b}$ & $\mathrm{R}^{2}$ & $\mathrm{k}$ & $\mathrm{a}$ & $\mathrm{b}$ & $\mathrm{R}^{2}$ & $\mathrm{k}$ & $\mathrm{a}$ & $\mathrm{b}$ \\
\hline $\begin{array}{l}\text { Henderson e } \\
\text { Pabis }\end{array}$ & 0,9834 & 0,0121 & 0,9185 & ------- & 0,9889 & 0,0125 & 0,9339 & & 0,9807 & 0,007 & 0,8774 & ----- \\
\hline Logarítmico & 0,9838 & 0,0094 & 0,9352 & $-0,2242$ & 0,9899 & 0,0114 & 0,9563 & $-0,0333$ & 0,9807 & 0,0068 & 0,8713 & $\overline{-} \overline{0}, 0060$ \\
\hline
\end{tabular}

$\mathrm{O}$ ajuste dos modelos aos dados experimentais está apresentado na Tabela 1.

Tabela 1. Valores do coeficiente de determinação $\left(\mathrm{R}^{2}\right)$ e Parâmetros obtidos dos modelos ajustados aos dados de secagem de extra do Baru, nas temperaturas de 50,60 e $70^{\circ} \mathrm{C}$.

Para o ajuste dos modelos matemáticos realizou-se análise de regressão não linear, pelo método Gauss-Newton, utilizando-se o programa computacional SigmaPlot.

Nas Figuras 1,2, e 3 são apresentados os dados das curvas de secagem nas temperaturas de 50,60 e $70^{\circ} \mathrm{C}$, respectivamente 


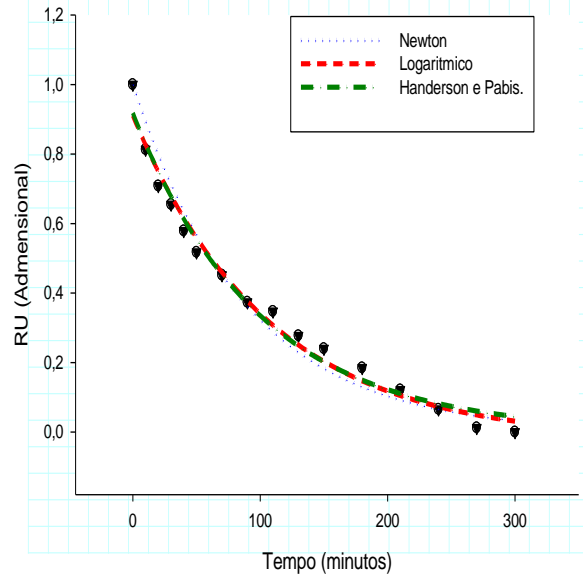

Figura 1. Curvas de secagem em função de temperatura $50^{\circ} \mathrm{C}$

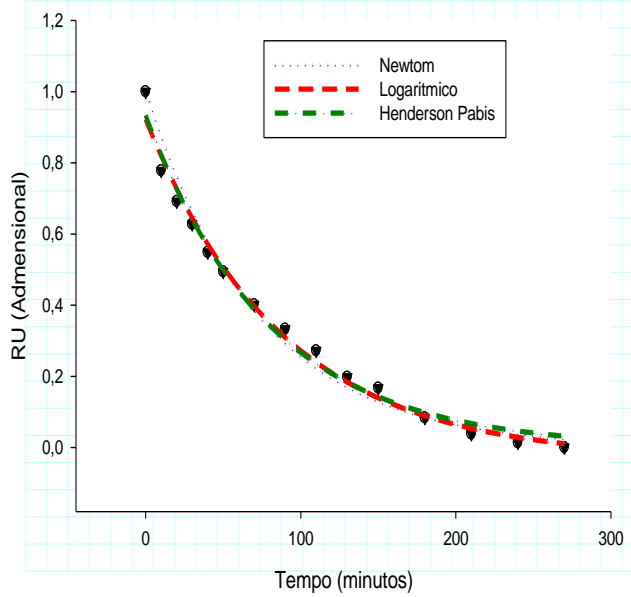

Figura 2. Curvas de secagem em função de temperatura $60^{\circ} \mathrm{C}$

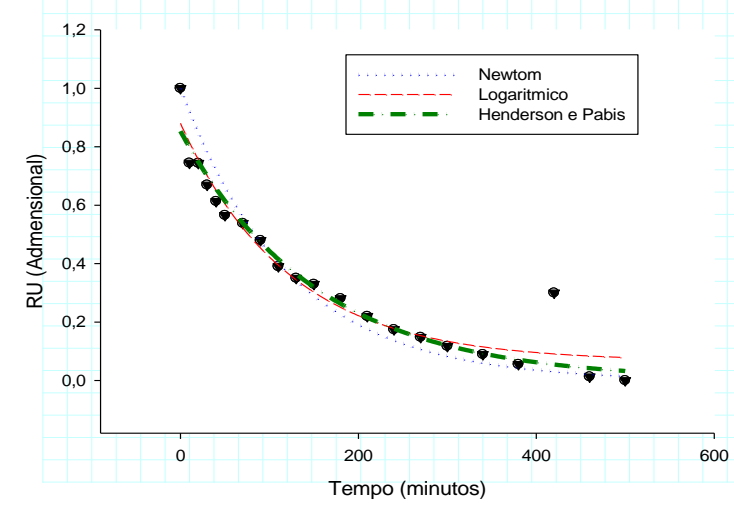

Figura 3. Curvas de secagem em função de temperatura $70^{\circ} \mathrm{C}$

Analisando os resultados dos modelos estudados mostram resultados bem próximos da realidade, podemos concluir que a cinética da Amêndoa Baru (Dipteryx alata) em secadores de bandejas a gás, nas três temperaturas estudadas, sendo o tempo de secagem inversamente proporcional à temperatura, conforme esperado. O modelo de melhor projeção para os ajustes aos dados experimentais nas três temperaturas de secagem foi o modelo Logarítmico, onde apresentar $\mathrm{R}^{2}>98 \%$. Para trabalho futuro, poderia ser feito novos estudos utilizando novos modelos.

Palavras-chave: Modelagem matemática, Ajuste de curvas, Cinética e Baru.

\section{Referências}

[1] DANTAS, T.N.P.; SOUZA JÚNIOR, F.E.; SOUZA, D.F.S.; MEDEIROS, M.F.D. Estudo da transferência de calor e massa e da cinética de secagem em placas planas de batata inglesa (Solanum Tuberosum L.). In VIII Congresso Brasileiro de Engenharia Química em Iniciação Científica. Uberlândia, MG, 2009

[2] GONELI, A.L.D. Dinâmica da variação das propriedades físico-mecânicas e da qualidade controladas. Tese de Doutorado. Universidade Federal de Viçosa. UFV. 2008.

[3] Park, K. J.; Vohnikoza, Z.; Brod, F. P. R. Evaluation of drying parameters and desorption isotherms of garden mint leaves (Mentha crispa L.). Journal of Food Engineering, Davis, v.51, n n.3, p.193-199, 2002.

[4] Romero-Penã, L. M.; Kieckbusch, T. G. Influências de condiçoes de secagem na qualidade de fatias de tomate. Brazilian Journal of Food Technology, Campinas, v.6, n.1. p69-76, 2003. 